\title{
Bacterial pathogens causing UTI and their antibiotic sensitivity pattern: a study from a tertiary care hospital from South India
}

\author{
Sneka P. ${ }^{1}$, Mangayarkarasi V. ${ }^{2}$ \\ ${ }^{1}$ Dr. P. Sneka, Assistant Professor, ${ }^{2}$ Dr. V. Mangayarkarasi, Professor and HOD; both authors are affiliated with the \\ Department of Microbiology, SRM Medical College Hospital and Research Centre, Kancheepuram, Tamil Nadu, India.
}

Corresponding Author: Dr. P. Sneka, Assistant Professor, Department of Microbiology, SRM Medical College Hospital and Research Centre, Kancheepuram, Tamil Nadu, India, Email Id : drsneka87@gmail.com

\begin{abstract}
Objectives: This study was conducted to find out the prevalence of pathogens causing UTI and their antibiotic sensitivity pattern. Materials and Methods: A Prospective study was carried out in the department of Microbiology for one year period from January to December 2018collaboratingwith the various clinical departments to determine the spectrum of organisms causing urinary tract infections and to determine their antibiotic susceptibility profile. Results: Among the 8303 samples tested significant bacteriuria was observed in $33.14 \%$. The incidence of UTI was more common in females and in the age group of 31-40 years. In this study, $1931(70.6 \%)$ gram negative bacilli and $756(27.4 \%)$ gram positive cocci were isolated, among which E.coli (61.2\%) was the commonest followed by Klebsiella (18.90\%), Pseudomonas (8.02 \%), Acinetobacter (4.4\%), Proteus (3.7\%) and Citrobacter (3.72\%). Among the gram positive organisms Entetrococcus (87.4\%) was the highest followed by Coagulase negative staphylococcusaureus (CONS) (7.9\%) and Staphlococcus aureus (4.6\%). Candida was isolated in 65cases (2.3\%). Imipenem (100\%) was the most susceptible antibiotic for Enterobacteriaciae followed by levofloxacin (83\%) and Amikacin (82\%). For the gram positive organisms Vancomycin (100\%) and Linezolid (100\%) was the most susceptible antibiotic followed by Nitrofurantoin (80\%) and Gentamycin (60\%). For both the gram positive and the gram negative organisms Nalidicacid, Norfloxacin, Cotrimoxazole and ampicillin were highly resistant and showed less than 30\%sensitivity. Conclusion: Knowledge of the pattern of organisms causing UTI and their sensitivity pattern is important in choosing empirical drugs in the treatment of UTI.
\end{abstract}

Keywords: Antibiotic susceptibility, Significant bacteriuria, E.coli, Staphylococcus aureus, Urinary tract infection

\section{Introduction}

Urinary tract infection (UTI) is defined as presence and active multiplication of microorganisms within the urinary tract. It is one of the major health problems affecting both sexes of all age group. In contrast to men, women are more susceptible to UTI and this is mainly due to short urethra, absence of prostatic secretion, pregnancy and ease of contamination of the urinary tract with fecal flora [1]. They are the frequent cause of nosocomial infections in many hospitals [2].

Gram negative bacteria like Escherichia coli, Proteus species, Klebsiella species, Pseudomonas aeruginosa, Acinetobacter, Serratia and Morganella morgagniae isolated from $75-95 \%$ cases of uncomplicated UTI which is most common in young, sexually active, non pregnant, premenopausal women [3]. The remaining

Manuscript received: $10^{\text {th }}$ June 2019

Reviewed: $20^{\text {th }}$ June 2019

Author Corrected: $24^{\text {th }}$ June 2019

Accepted for Publication: 27 $7^{\text {th }}$ June 2019 cases are associated with a variety of organisms, including the gram positive bacteria like Enterococcus, Staphylococcus especially coagulase negative staphylococci, Streptococcus agalactiae and other less frequently isolated organisms [4]. E. coli is responsible to most UTIs [5].

The distribution of antimicrobial susceptibility data of UTI-causing microorganisms changes from time to time and from place to place [6]. Drug resistance among bacteria causing UTI has increased since introduction to UTI chemotherapy [7].

The Infectious Disease Society of America recommends that physicians to keep updating information on local susceptibility pattern of organisms causing urinary tract infections and to monitor changes in their susceptibility which is a prerequisite for any hospital infection control program [8]. 
Original Research Article

UTIs are often treated with different broad-spectrum antibiotics. In the view of the increasing bacterial resistance, regular monitoring of resistance patterns is necessary to improve guidelines for empirical antibiotic therapy [9]. To ensure appropriate therapy, current local based knowledge of the organisms that cause UTI and their antibiotic susceptibility testing is mandatory [10].

\section{Materials and Methods}

Duration and type of study: A prospective study was conducted for an one year period from January 2017 to December 2018 at SRM Medical college hospital and research centre collaborating with Medicine, Paediatric, Obstetrics, Orthopedics, Urology, Surgery, Nephrology, General Medicine and Dermatology departments. Prior approval from the institutional ethical committee [Ethics clearance number 1286/IEC/2017] and informed consent was obtained from the patient. The study involved both the sexes and all age groups. A total of 8303 urine samples were collected.

Inclusion criteria: All patients with a presumptive diagnosis of UTI were included in the study.

Data collection procedure: After proper instruction clean catch mid stream urine (MSU) sample was collected in a wide mouthed sterile container. The collected samples were labeled and transported to the microbiology laboratory and processed within 2 hours. Urine was examined macroscopically for the colour and turbidity and wet mount for the number of pus cells, bacteria and budding yeast cells. Culture was done by inoculatingin Blood agar and Mac Conkey agar and incubating at $37^{\circ} \mathrm{C}$ for $18-24$ hours. Growth of $>10^{5} \mathrm{cfu} / \mathrm{ml}$ in the culture plates was considered positive. Further identification and confirmation was done by colony morphology, motility and biochemical tests as per the standard operating procedures.

Antibiotic susceptibility testing: Antibiotic susceptibility testing was done on Muller Hinton Agar by Kirby Bauer's disc diffusion method as per Clinical Laboratory Standards Institute (CLSI) guidelines. Identical colonies of bacterium was selected and inoculated in to peptone water broth and incubated for 2 hours at $37^{\circ} \mathrm{C}$. After adjusting to $0.5 \mathrm{Mc}$ Farlands standard the test organism was streaked on to Muller hinton agar plate by a sterile swab.

The following antibiotic discs (drug concentrations in $\mu \mathrm{g})$ were used: Amikacin $(30 \mu \mathrm{g})$ Gentamicin $(10 \mu \mathrm{g})$, Ceftazidime $(30 \mu \mathrm{g})$, Cotrimoxazole $(25 \mu)$, Norfloxacin $(10 \mu)$, Levofloxacin $(5 \mu)$, Ampicillin $(10 \mu \mathrm{g})$, Cefepime $(30 \mu \mathrm{g})$, Nalidixic acid $(30 \mu \mathrm{g})$, Nitrofurantoin $(300 \mu \mathrm{g})$, Imipenem $(10 \mu \mathrm{g})$ and Piperacillin-Tazobactum $(10 \mu \mathrm{g} / 100 \mu \mathrm{g})$ were used for gram negative organisms.

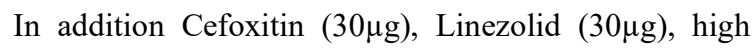
level Gentamicin $(120 \mu \mathrm{g})$ and Vancomycin $(30 \mu \mathrm{g})$ were used for gram positive organisms.

Quality control strains used were:

- Staphylococcus aureus ATCC 25923,

- Enterococcus faecalis ATCC 29212,

- Escherichia coli ATCC 25922,

- Pseudomonas aeruginosa ATCC 27853.

\section{Results}

The total number of urine samples received in the microbiology laboratory was 8303 . Of the total $2752(33.14 \%)$ were positive for growth. Out of the positive isolates 1931 (70.16\%) samples yielded the growth of gram negative bacilli, 756 (27.47\%) samples yielded the growth of gram positive cocci and 65 (2.36 \%) samples yielded the growth of candida spp. Overall distribution of the pathogens causing UTI is shown in the Figure 1.

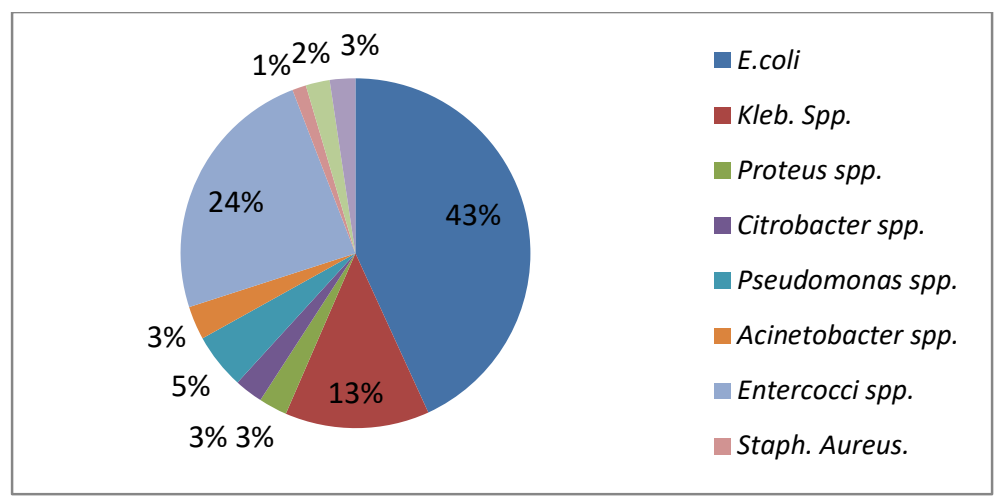

Figure-1: Distribution of isolates in UTI $(\mathrm{N}=2752)$

The distribution of the gram-negative organisms causing UTI is depicted in table 1. 
Table-1: Distribution of gram negative organisms causing UTI.

Original Research Article

\begin{tabular}{|c|c|c|}
\hline Organism & $\begin{array}{c}\text { Total gram negatives } \\
\text { (Total n=1931) }\end{array}$ & Percentage (\%) \\
\hline E.coli & 1182 & 61.21 \\
\hline Klebsiella pneumonia & 365 & 18.90 \\
\hline Pseudomonas aeruginosa & 155 & 8.02 \\
\hline Acinetobacterspp & 85 & 4.40 \\
\hline Proteus spp & 72 & 3.72 \\
\hline Citrobacterspp & 72 & 3.72 \\
\hline
\end{tabular}

Table-2: Distribution of gram positive organisms causing UTI.

\begin{tabular}{|c|c|c|}
\hline Organism & $\begin{array}{c}\text { Total gram positives } \\
\text { (Total } \mathbf{n = 7 5 6} \text { ) }\end{array}$ & Percentage (\%) \\
\hline Enterococcus spp & 661 & 87.43 \\
\hline CONS & 60 & 7.93 \\
\hline Staphylococcus aureus & 35 & 4.62 \\
\hline
\end{tabular}

Table-3: Age wise distribution of UTI

\begin{tabular}{|c|c|c|}
\hline Age (in years) & Positive cultures & Percentage (\%) \\
\hline $0-10$ & 65 & 2.36 \\
\hline $11-20$ & 158 & 5.74 \\
\hline $21-30$ & 480 & 17.4 \\
\hline $31-40$ & 920 & 33.4 \\
\hline $41-50$ & 514 & 18.6 \\
\hline $51-60$ & 302 & 10.9 \\
\hline $61-70$ & 228 & 8.28 \\
\hline $71-80$ & 85 & 3.08 \\
\hline
\end{tabular}

Table-4: Sex wise distribution of UTI.

\begin{tabular}{|c|c|c|}
\hline Sex & Culture Positives & Percentage (\%) \\
\hline Female & 1620 & 58.86 \\
\hline Male & 1132 & 41.13 \\
\hline
\end{tabular}

Table-5: Ward wise distribution of the positive cases

\begin{tabular}{|c|c|c|}
\hline Ward & Total number & Percentage (\%) \\
\hline Medicine & 417 & 15.15 \\
\hline Surgery & 350 & 12.71 \\
\hline Paediatrics & 762 & 27.68 \\
\hline Obstretics & 891 & 32.37 \\
\hline Urology & 214 & 7.7 \\
\hline Nephrology & 116 & 4.2 \\
\hline Dermatology & 02 & 0.07 \\
\hline
\end{tabular}


Table-6: Overall sensitivity of the pathogens causing UTI.

Original Research Article

\begin{tabular}{|c|c|c|}
\hline Antibiotic & Sensitive & Resistant \\
\hline Imipenem & $100 \%$ & $0 \%$ \\
\hline Vancomycin & $100 \%$ & $0 \%$ \\
\hline Linezolid & $100 \%$ & $18 \%$ \\
\hline Amikacin & $82 \%$ & $65 \%$ \\
\hline Gentamycin & $35 \%$ & $80 \%$ \\
\hline Norfloxacin & $20 \%$ & $17 \%$ \\
\hline Levofloxacin & $83 \%$ & $14 \%$ \\
\hline Nitrofurantoin & $66 \%$ & $88 \%$ \\
\hline Cotrimoxazole & $12 \%$ & $22 \%$ \\
\hline Cefepime & $78 \%$ & $16 \%$ \\
\hline Cefoxitin & $84 \%$ & $85 \%$ \\
\hline Ampicillin & $15 \%$ & $72 \%$ \\
\hline Nalidixic acid & $28 \%$ & $16 \%$ \\
\hline Piperacillin-tazobactem & $84 \%$ & $44 \%$ \\
\hline High level gentamycin & $56 \%$ & $0 \%$ \\
\hline
\end{tabular}

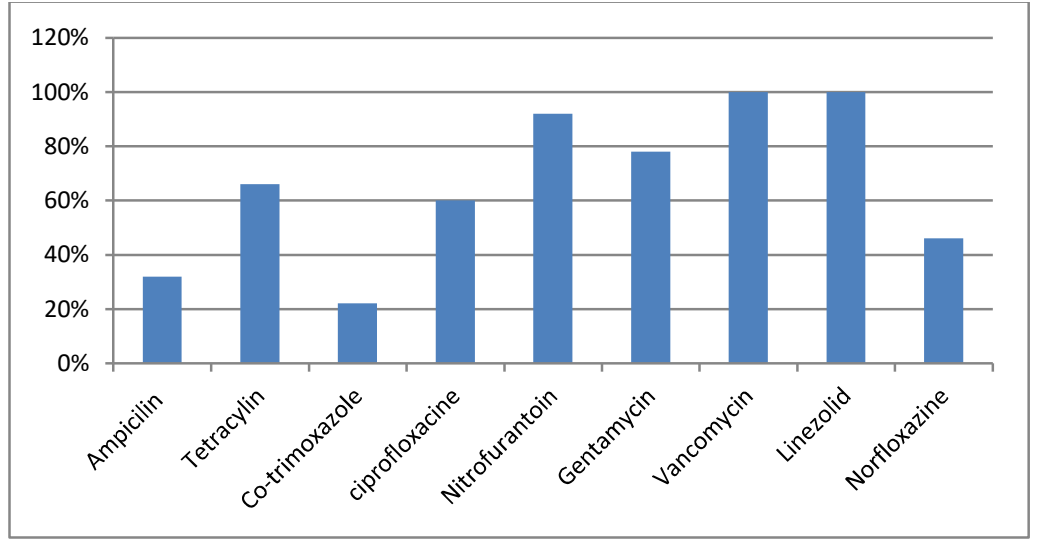

Figure 2: Antibiogram of the gram positive organisms

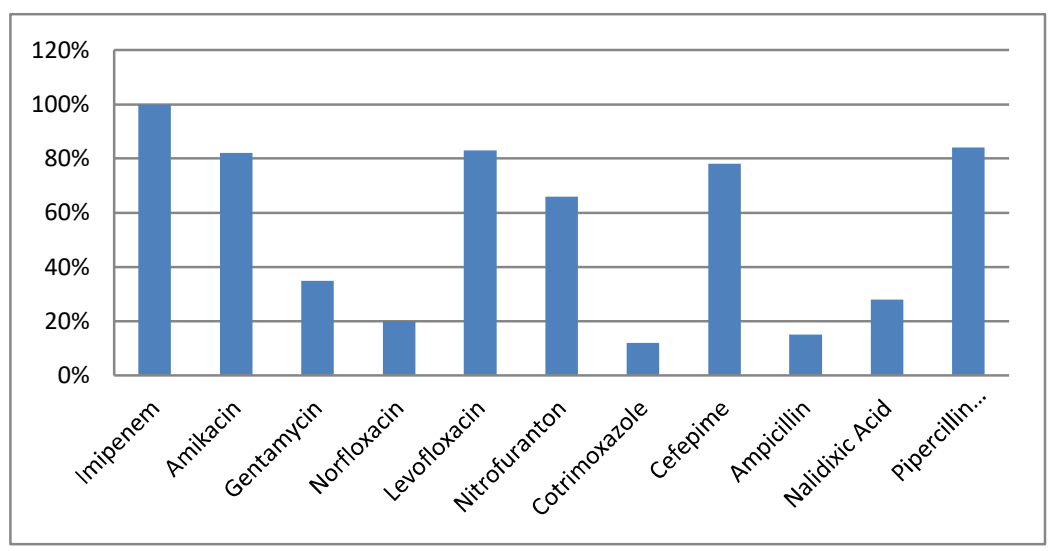

Figure 3: Antibiogam of the gram negative organisms

Among the gram positive cocci the highest was Enterococcus spp 661 (87.43\%) followed by CONS 60 (7.93\%z) and Staphylococcus aureus 35 (4.62\%) as depicted in Table 2. Candida was grown in 65 (2.36) of the total samples received. 


\section{Original Research Article}

The samples collected were from age group of 10 months to 84 years. The mean age of positive culture was between 31 40 years as shown in Table 3.

Of the positive culture samples the majority were females $1620(58.86 \%)$ when compared to 1132 males $(41.13 \%)$ as shown in Table 4.

The total number of positive case were more from more obstetricsward $(32.37 \%)$ followed by paediatric $(27.68 \%)$, Medicine (15.15\%), Surgery (12.71\%), Urology (7.7\%), Nephrology (4.2\%) and dermatology $(0.07 \%)$ as shown in Table 5.

For the gram positive organisms the most susceptible antibiotic was Vancomycin and Linezolid and the least susceptible was Cotrimoxazole, Ampicillin and Norfloxacin as shown in Figure 2.

In the case of gram negative organisms the most susceptible antibiotic was Imipenem followed by Levofloxacin and Amikacin. The least susceptible antibiotics were Cotrimoxazole, Ampicillin and Norfloxacin as shown in Figure 3

\section{Discussion}

UTIs are one of the most common infection diagnosed worldwide. Availability of new antimicrobials has improved the management of UTIs. However, the management of UTIs has become difficult due to the emergence of antimicrobial drug resistance.

The prevalence rate in this study was $33.14 \%$ which is relatively higher than studies conducted in other parts of India $[11,12]$. The prevalence rate is similar to study by Shanthi et al showing 32\% [13] and studies from northeast India showing a prevalence rate of $30 \%$ [14]. Gram negative organisms $(70.16 \%)$ causing UTI was higher when compared to gram positive organisms (27.14\%) [12].

Among the gram negative organisms E.coli (61.21\%) was the most common organism isolated followed by klebsiella pneumoniae (18.90\%), Pseudomonas aeruginosa (8.02\%), Acinetobacter spp (4.40\%), Proteus spp (3.72\%) and citrobacterspp (3.72\%). Other authors observed $E$. coli as the most common isolated organism in their studies also $[12,13,14,15]$. This indicates there is no much change in the pathogens causing UTI. However, the isolation rates are lower when compared to other studies $[16,17,18]$. The possible explanation could be either low prevalence in the area or a few patients would have received their first dose of antibiotic before collecting the sample. Statistically significant difference was observed between genders as majority of the pathogens were isolated from females $(P<0.001)$.

This is similar to other national and international studies showing higher prevalence in females $[11,13,16]$. The reason behind this high prevalence of UTI in females is due to close proximity of the urethral meatus to the anus, shorter urethra, sexual intercourse, incontinence, and bad toilet $[19,20,21]$. Statically significant association was observed for prevalence of uropathogens among age groups $(P=0.011)$ where uropathogens were more from obstretrics (32.37\%) followed by paediatric $(27.68 \%)$ in this study, which is similar to studies by Desai et al [22] from Mumbai and Ullahet from Pakistan [23], whereas studies by Sarasu et al showed higher percentage from paediatric age group followed by obstretrics [16].

Overall, resistance among the isolates was maximum for Cotrimoxazole (88\%) followed by Norfloxacin $(80 \%)$ as shown in Table 6. This could be because of frequent prescription of these drugs as the first-line treatment of UTI in the hospital. Similar results were reported by Chongtham et al. A generalized reduction in bacterial susceptibility toward quinolones has been observed which could be because it is one of the drugs of choice for the treatment of UTI [14]. This finding was also consistent with a study done in Karnataka by Eswarappa $\mathrm{M}$ et al who reported a high rate of resistance against quinolones [11].

The resistance to cotrimoxazole in this study is high compared to studies from other parts of the world [24, 25].Amikacin and Levofloxacin were highly susceptible and showed a resistance of $18 \%, 17 \%$ respectively, whereas Gentamycin was susceptible in only $35 \%$ cases.

A generalized reduction in the activity for Ampicillin was seen in both the gram positive and gram negativeisolates causing UTI. For Pseudomonas aeroginosa, Piperacillin-tazobactem was highly effective and showed only $16 \%$ resistance. All the gram positive cocci isolated in the study were sensitive to Vancomycin and Linezolid (100\%) but other studies have shown low level resistance to these drugs $[15,26]$. Majority of the gram positive cocci were sensitive to 


\section{Original Research Article}

nitrofurantoin (92\%). In the case of gram negative organisms the resistance to Norfloxacin and cotrimoxazole was high and is $54 \%$ and $78 \%$ respectively. The resistance pattern observed in this study is similar to the study by Naik et al from Karnataka [27]. Drug resistance among uropathogens has increased over the past few decades because of their widespread indiscriminate use, easy availability, and over the counter sale.

\section{Conclusion}

It is important to know the most common organism causing UTI in a particular hospital setting. The knowledge of antimicrobial pattern of routinely isolated uropathogens in that particular hospital may provide guidance to clinicians regarding the empirical treatment of UTI. Data on the changing or increasing antibiotic resistance would guide the clinicians in preventing the unnecessary use, misuse or overuse of antibiotics. All these measures will curtail the emergence of drug resistance.

Acknowledgement: All the authors have contributed in the research work and in framing of the article.

Findings: Nil; Conflict of Interest: None initiated Permission from IRB: Yes

\section{References}

1. Alemu A, Moges F, Shiferaw Y, et al. Bacterial profile and drug susceptibility pattern of urinary tract infection in pregnant women at University of Gondar Teaching Hospital, Northwest Ethiopia. BMC Res Notes. 2012 Apr 25; 5:197. DOI: 10.1186/1756-05005-197.

2. Warren JW. Catheter-associated urinary tract infections. Infect Dis Clin North Am. 1997 Sep;11(3): 609-22.

3. Hooton TM. Clinical practice. Uncomplicated urinary tract infection. N Engl J Med. 2012 Mar 15;366(11): 1028-37. DOI:10.1056/NEJMcp1104429

4. Wagenlehner FM, Naber KG. Current challenges in the treatment of complicated urinary tract infections and prostatitis. ClinMicrobiol Infect. 2006 May;12Suppl 3:67-80. DOI:10.1111/j.1469-0691.2006.01398.x

5. Beyene G, Tsegaye W. Bacterial uropathogens in urinary tract infection and antibiotic susceptibility pattern in jimma university specialized hospital, southwest ethiopia. Ethiop J Health Sci. 2011 Jul;21(2): 141-6. DOI:10.4314/ejhs.v21i2.69055.
6. Okonko IO, Ijandipe LA, Ilusanya OA, et al. Incidence of urinary tract infection (UTI) among pregnant women in Ibadan, South-Western Nigeria. African Journal of Biotechnology. 2009; 8 (23): 6649-6657.

7. Nerurkar A, Solanky P, Naik SS. Bacterial pathogens in urinary tract infection and antibiotic susceptibility pattern. J Pharm Biomed Sci 2012; 21: 1-3.

8. Moue A, AktaruzzamanSAQM, Ferdous N, Karim R, Khalil MMR, Das AK. Prevalence of urinary tract infection in both outpatient department and in patient department at a medical college setting of Bangladesh. International Journal of Biosciences 2015;7(5): 146-152

9. Kripke C. Duration of therapy for women with uncomplicated UTI. Am Fam Physician. 2005 Dec 1;72 (11): 2219.

10. Kahlmeter G; ECO.SENS. An international survey of the antimicrobial susceptibility of pathogens from uncomplicated urinary tract infections: the ECO.SENS Project. J AntimicrobChemother. 2003 Jan;51(1):69-76. DOI: $10.1093 / \mathrm{jac} / \mathrm{dkg} 028$

11. Eshwarappa M, Dosegowda R, Aprameya IV, et al. Clinico-microbiological profile of urinary tract infection in south India. Indian J Nephrol. 2011 Jan; 21(1):30-6. DOI: $10.4103 / 0971-4065.75226$.

12. Akram M, Shahid M, Khan AU. Etiology and antibiotic resistance patterns of community-acquired urinary tract infections in J N M C Hospital Aligarh, India. Ann Clin Microbiol Antimicrob. 2007 Mar 23; 6:4. DOI: 10.1186/1476-0711-6-4

13. Kumari SS, Ramya T, Reddy K, Swarnalatha G, Swapna V, Reddy BS, et al. Aetiology and antibiotic resistance pattern of uropathogens in a tertiary care hospital. J Evol Med Dent Sci 2016; 5: 5534-8.

14. Chongtham U, Yengkokpam C, Lokhendro H. Bacterial uropathogens in urinary tract infection and antibiotic susceptibility pattern of patients attending JNIMS hospital, Imphal. J EvolMed Dental Sci 2013;2: 9769-74.

15. Vohra P, Mengi S, Bunger R, Garg S, Pathania D, Singh VA. Bacterial uropathogens in urinary tract infection and their antibiotic susceptibility pattern in a tertiary care hospital. Int J CurrMicrobiol App Sci 2015;4:612-45. 


\section{Original Research Article}

16. V.P. Sarasu, Rani S.R.Bacteriological profile and antibiogram of urinary tract infections at a tertiary care hospital. International Journal of Medical Microbiology and Tropical diseases 2017;3(3):106-112

17. Bahadin J, Teo SS, Mathew S. Aetiology of community- acquired urinary tract infection and antimicrobial susceptibility patterns of uropathogens isolated. Singapore Med J. 2011 Jun;52(6):415-20.

18. Tseng MH, Lo WT, Lin WJ, et al. Changing trend in antimicrobial resistance of pediatric uropathogens in Taiwan. Pediatr Int. 2008 Dec;50(6):797-800. DOI: 10.1111/j.1442-200X.2008.02738.x.

19. Ochei J, Kolhatkar A. Medical Laboratory Science Theory and Practicereprint. 6th edition. New Delhi, India: McGraw-Hill; 2007. Diagnosis of infection by specific anatomic sites/antimicrobial susceptibility tests; pp. 615-643, 788-798.

20. Aiyegoro OA, Igbinosa OO, Ogunmwonyi IN, Odjadjaro E, Igbinosa OE, Okoh AI. Incidence of urinary tract infections (UTI) among children and adolescents in Ile-Ife, Nigeria. African Journal of Microbiological Research. 2007;1:13-19.

21. Orrett FA, Davis GK. A comparison of antimicrobial susceptibility profile of urinary pathogens for the years, 1999 and 2003. West Indian Med J. 2006 Mar; 55 (2): 95-9. DOI:10.1590/s0043-3144200600 0 200006
22. Desai P, Ukey PM, Chauhan AR, Malik S, Mathur M. Etiology and antimicrobial resistance patterns of uripatyhogens in a hospital from suburb of Mumbai. Int J Biol Med Res 2012; 3: 2007-2012.

23. Ullah F, Malik SA, Ahmed J. Antimicrobial susceptibility pattern and ESBL prevalence in Klebsiella pneumoniae from urinary tract infections in the North-West of Pakistan. African Journal of Microbiology Research. 2009 Nov 30;3(11):676-80.

24. Vromen M, van der Ven AJ, et al. Antimicrobial resistance patterns in urinary isolates from nursing home residents. Fifteen years of data reviewed. J AntimicrobChemother. 1999 Jul;44(1):113-6. DOI:10. 1093/ jac/44.1.113

25. Kahlmeter G. Prevalence and antimicrobial susceptibility of pathogens in uncomplicated cystitis in Europe. The ECO. SENS study. INT J Antimicrob Agents. 2003 Oct; 22 Suppl 2:49-52. DOI: https://doi. org/ 10. 1016/ S0924-8579(03)00229-2

26. Sood S, Gupta R. Antibiotic resistance pattern of community acquired uropathogens at a tertiary care hospital in Jaipur, Rajasthan. Indian J Community Med 2012; 37:39-44. DOI: https://dx.doi.org/ 10.4103\%2 F0970- 0218.94023

27. Naik TB, Lavanya J, Upadhya A, Mani V. Gram positive uropathogens and their antibiogram: Data analysis at a tertiary care hospital in Karnataka. Indian J Microbiol Res 2018;5(1):71-75. DOI: 10.18231/23945478. 2018.0014

\section{How to cite this article?}

Sneka P, Mangayarkarasi V. Bacterial pathogens causing UTI and their antibiotic sensitivity pattern: a study from a tertiary care hospital from South India. Trop J Path Micro 2019;5(6):379-385. doi:10.17511/jopm.2019.i06.08. 